\title{
BILANGAN RAINBOW CONNECTION UNTUK BEBERAPA GRAF CORONA SISI
}

\author{
NURHASANAH, SYAFRIZAL SY, LYRA YULIANTI \\ Program Magister Jurusan Matematika, \\ Fakultas Matematika dan Ilmu Pengetahuan Alam, Universitas Andalas, \\ Kampus UNAND Limau Manis Padang, Indonesia, \\ motoxtrail@gmail.com
}

\begin{abstract}
Abstrak. Suatu lintasan $u P v$ dikatakan sebagai rainbow path pada $G$ jika tidak ada dua sisi pada $P$ yang berwarna sama. Suatu graf $G$ dikatakan rainbow-connected terhadap pewarnaan sisi-sisi, jika $G$ memuat lintasan rainbow $u-v$ untuk setiap dua titik $u$ dan $v$ pada $G$. Suatu pewarnaan sisi dimana $G$ bersifat rainbow connected dinamakan rainbow coloring terhadap $G$. Pada tulisan ini akan ditentukan bilangan rainbow connection untuk corona sisi dari beberapa graf sederhana, yaitu $r c(G \diamond H)$ untuk $G$ atau $H$ adalah graf lengkap $K_{n}$, graf lintasan $P_{n}$ dan graf siklus $C_{n}, n \geq 3$.
\end{abstract}

Kata Kunci: Graf lengkap, lintasan, siklus, bilangan rainbow connection

\section{Pendahuluan}

Konsep dari rainbow connection diperkenalkan oleh Chartrand [2] pada tahun 2008. Misalkan $G$ merupakan suatu graf terhubung nontrivial, definisikan suatu pewarnaan $c: E(G) \rightarrow\{1,2, \cdots, n\}, n \in \mathrm{N}$, dimana sisi yang bertetangga boleh berwarna sama. Suatu lintasan $u P v$ dikatakan sebagai rainbow path pada $G$ jika tidak ada dua sisi pada $P$ yang berwarna sama. Suatu graf $G$ bersifat rainbow-connected terhadap pewarnaan sisi-sisi, jika $G$ memuat lintasan rainbow $u-v$ untuk setiap dua titik $u$ dan $v$ pada $G$. Suatu pewarnaan sisi yang menyebabkan $G$ rainbow connected dinamakan rainbow coloring terhadap $G$. Bilangan rainbow connection (rainbow connection number) dari $G$ dilambangkan dengan $r c(G)$, didefinisikan sebagai minimum dari banyaknya warna yang diberikan pada $G$ sedemikian sehingga $G$ merupakan graf terhubung (rainbow connected).

Misalkan $c$ merupakan suatu pewarnaan rainbow dari graf terhubung $G$. Untuk dua titik $u$ dan $v$ pada $G$, suatu rainbow $u-v$ geodesic pada $G$ adalah lintasan rainbow $u-v$, dengan panjang lintasan $u-v$ merupakan jarak antara titik $u$ dan $v$. Graf $G$ merupakan strongly rainbow connected jika $G$ memuat suatu rainbow $u-v$ geodesic untuk setiap dua titik pada $G$. Jika $G$ strongly rainbow connected maka pewarnaan $c$ dinamakan strong rainbow connection number $\operatorname{src}(G)$ terhadap $G$. Suatu strong rainbow coloring dari $G$ dengan menggunakan $\operatorname{src}(G)$ warna dinamakan sebagai suatu minimum strong rainbow coloring dari $G$. Sehingga $r c(G) \leq \operatorname{src}(G)$ untuk setiap graf terhubung $G$. 


\section{Corona Sisi pada Beberapa Graf}

Corona yang dari beberapa graf dibedakan menjadi dua, yaitu graf corona yang diperkenalkan oleh Frucht dan Harary [7] dan graf corona sisi yang diperkenalkan oleh Hou dan Shiu [4]. Graf corona antara graf $G$ dan $H$ dinotasikan dengan $G \circ H$, sedangkan graf corona sisi dilambangkan dengan $G \diamond H$.

Definisi 2.1. [4] Misalkan graf $G$ dan $H$ mempunyai $m$ dan $n$ titik, serta $p$ dan $q$ sisi. Graf corona sisi $G$ dan $H$ atau $G \diamond H$ didefinisikan sebagai suatu graf yang dikonstruksi dari satu graf $G$ dan $p$ duplikat dari $H$, yaitu $H_{i}, i=1,2, \cdots, p$, dimana titik ujung setiap sisi ke-i pada $G$ terhubung pada setiap titik $H$ di setiap ke-p copynya.

Berdasarkan definisi, diperoleh bahwa graf corona sisi $G \diamond H$ memiliki $m+p n$ titik dan $p+2 p n+p q$ sisi. Banyaknya sisi pada suatu graf $G$ dikatakan sebagai ukuran dari $G$.

\section{Bilangan Rainbow Connection pada Beberapa Graf}

Jika $G$ merupakan graf terhubung nontrivial berukuran $m$, maka $\operatorname{diam}(G) \leq$ $r c(G) \leq \operatorname{src}(G) \leq m$, dimana $\operatorname{diam}(G)$ merupakan diameter pada $G$.

Proposisi 3.1. [2] Misalkan $G$ merupakan graf terhubung nontrivial berukuran $m$. Maka

(1) $\operatorname{rc}(G)=1$ jika dan hanya jika $G$ merupakan graf lengkap, $\operatorname{src}(G)=1$ jika dan hanya jika $G$ merupakan graf lengkap,

(2) $\operatorname{rc}(G)=2$ jika dan hanya jika $\operatorname{src}(G)=2$,

(3) $r c(G)=m-1$ jika dan hanya jika graf $G$ merupakan graf pohon, $\operatorname{src}(G)=m-1$ jika dan hanya jika graf $G$ merupakan graf pohon.

Proposisi 3.2. [2] Untuk setiap bilangan bulat positif $n \geq 4$ berlaku

$$
r c\left(C_{n}\right)=\operatorname{src}\left(C_{n}\right)=\left\lceil\frac{n}{2}\right\rceil .
$$

\section{Bilangan Rainbow Connection untuk Corona Sisi Beberapa Graf}

Pada teorema berikut ini disajikan bilangan rainbow connection untuk graf corona sisi graf lengkap dua titik dengan beberapa graf tertentu yaitu graf lintasan, graf siklus dan graf lengkap.

Teorema 4.1. Misalkan terdapat graf $G \cong K_{2}$. Maka

$$
r c\left(K_{2} \diamond H\right)= \begin{cases}1, & \text { untuk } H \cong K_{n}, n \geq 1 \\ 2, & \text { untuk } H \cong P_{n}, 3 \leq n \leq 12, \text { atau } \\ \text { untuk } H \cong C_{n}, 4 \leq n \leq 12, \\ 3, \text { untuk } H \cong P_{n}, n \geq 13, \text { atau } \\ \text { untuk } H \cong C_{n}, n \geq 13 .\end{cases}
$$

Bukti. Perhatikan dua kasus berikut. 
(Kasus 1.) Untuk $G \cong K_{2}$ dan $H \cong K_{n}$.

Berdasarkan definisi graf corona sisi, maka graf $K_{2} \diamond K_{n} \cong K_{2+n}$ merupakan graf lengkap, maka berdasarkan Proposisi 3.1(1) diperoleh $r c\left(K_{2} \diamond K_{n}\right)=$ $r c\left(K_{2+n}\right)=1$.

(Kasus 2.) Bagian 1. Untuk $G \cong K_{2}$ dan $H \cong P_{n}$ dengan $3 \leq n \leq 12$.

Misalkan himpunan titik pada $K_{2}$ adalah $V\left(K_{2}\right)=\left\{x_{1}, x_{2}\right\}$ dan himpunan titik pada $P_{n}$ adalah $V\left(P_{n}\right)=\left\{y_{1}, y_{2}, \cdots y_{n}\right\}, E\left(P_{n}\right)=\left\{y_{i} y_{i+1} ; i=\{1,2, \cdots, n-1\}\right.$. Definisikan suatu 2 - coloring pada sisi-sisi $P_{n}, 3 \leq n \leq 12$ sebagai berikut.

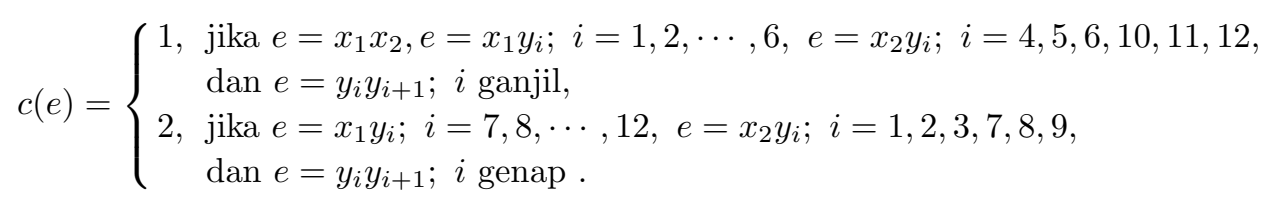

Maka $c(e)=2$ untuk setiap $e \in E\left(K_{2} \diamond P_{n}\right), 3 \leq n \leq 12$ akan terdapat rainbow 2-coloring. Ini akan mengakibatkan $r c\left(K_{2} \diamond P_{n}, 3 \leq n \leq 12\right) \leq 2$. Karena $K_{2} \diamond P_{n}$ bukan graf lengkap, maka $r c\left(K_{2} \diamond P_{n}, 3 \leq n \leq 12\right)>1$. Jelas bahwa $1<r c\left(K_{2} \diamond P_{n}, 3 \leq n \leq 12\right) \leq 2$ maka haruslah $r c\left(K_{2} \diamond P_{n} ; 3 \leq n \leq 12\right)=2$. Bagian 2. Untuk $G \cong K_{2}$ dan $H \cong C_{n}$ dengan $4 \leq n \leq 12$.

Dengan metode pembuktian yang sama dengan Kasus 2 bagian 1, diperoleh bahwa $r c\left(K_{2} \diamond C_{n} ; 4 \leq n \leq 12\right)=2$.

(Kasus 3.) Bagian 1. Untuk $G \cong K_{2}$ dan $H \cong P_{n}$ dengan $n \geq 13$.

Misalkan $x$ dan $y$ adalah titik pada $K_{2}$ dan $V\left(P_{n}\right)=\left\{v_{1}, v_{2}, \cdots v_{n}\right\}$. Definisikan suatu pewarnaan pada sisi-sisi $K_{2} \diamond P_{n} ; n \geq 13$ yaitu 3-coloring $c: E\left(K_{2} \diamond\right.$ $\left.P_{n} ; n \geq 13\right) \rightarrow\{1,2,3\}$ sebagai berikut. Berikan pewarnaan

$$
c(t z)=\left\{\begin{array}{l}
1, \text { jika } t z=x v_{i}, \quad i=1,2, \cdots, n, \\
2, \text { jika } t z=y v_{i}, \quad i=1,2, \cdots, n-1, \\
3, \text { jika } t z=x y
\end{array}\right.
$$

maka akan terdapat rainbow path $v_{i} P v_{j}$ yaitu $v_{i} x y v_{j} ; v_{i} v_{j} \in P_{n} ; j=$ $\{1,2, \cdots, n\}$. Karena $\operatorname{diam}\left(K_{2} \diamond P_{n} ; n \geq 13\right)=2$, maka $r c\left(K_{2} \diamond P_{n} ; n \geq 13\right) \geq 2$. Asumsikan bahwa $\operatorname{rc}\left(K_{2} \diamond P_{n} ; n \geq 13\right)=2$. Misalkan $c^{\prime}$ merupakan rainbow 2coloring dari $\left(K_{2} \diamond P_{n} ; n \geq 13\right)$. Pilihlah pewarnaan pada sisi $c^{\prime}\left(x v_{j}\right)=1$, $c^{\prime}\left(y v_{j}\right)=2 ; j=1,2, \cdots, n-1$. Kemudian berikan pewarnaan sisi-sisi pada $P_{n}$ dengan $c^{\prime}\left(v_{i} v_{i+1}\right)=1$ dan $c^{\prime}\left(v_{i+1} v_{i+2}\right)=2$. Maka untuk dua titik yang tidak bertetangga pada $P_{n}$, diperoleh bahwa $c^{\prime}\left(x v_{i}\right)=c^{\prime}\left(x v_{j}\right)$, sehingga tidak terdapat rainbow path pada $P_{n}$. Sehingga haruslah $r c\left(K_{2} \diamond P_{n} ; n \geq 13\right)>2$. Diperoleh $2<\operatorname{rc}\left(K_{2} \diamond P_{n} ; n \geq 13\right) \leq 3$ maka haruslah $r c\left(K_{2} \diamond P_{n} ; n \geq 13\right)=3$. Bagian 2. Untuk $G \cong K_{2}$ dan $H \cong C_{n}$ dengan $n \geq 13$.

Dengan metode pembuktian yang sama dengan kasus 3 bagian 1, Misalkan $V\left(K_{2}\right)=\left\{x_{1}, x_{2}\right\}$ dan himpunan titik pada $C_{n}$ adalah $V\left(C_{n}\right)=\left\{y_{1}, y_{2}, \cdots y_{n}\right\}$, $E\left(C_{n}\right)=\left\{y_{i} y_{i+1}\right\}$ maka akan diperoleh $\operatorname{rc}\left(K_{2} \diamond C_{n} ; n \geq 13\right)=3$.

Pada teorema berikut ini akan diberikan bilangan rainbow connection untuk beberapa graf corona sisi dari graf lengkap, graf lintasan dan graf siklus masingmasing dengan graf lengkap. 
Teorema 4.2. Bilangan rainbow connection untuk beberapa graf corona sisi $G \diamond H$ dengan $H \cong K_{n} ; n \geq 1$ adalah sebagai berikut.

$$
r c\left(G \diamond K_{n}\right)= \begin{cases}3, & \text { untuk } G \cong K_{m} ; m \geq 4, \\ m-1, & \text { untuk } G \cong P_{m} ; m \geq 3, \\ \left\lfloor\frac{m}{2}\right\rfloor+1, & \text { untuk } G \cong C_{m} ; m \geq 3 .\end{cases}
$$

Bukti. Perhatikan tiga kasus berikut.

(Kasus 1.) Untuk $G \cong K_{m}$ dan $H \cong K_{n}$ merupakan graf lengkap.

Definisikan suatu pewarnaan pada sisi-sisi $K_{m} \diamond K_{n} ; m \geq 4$ yaitu 3-coloring $c: E\left(P_{n}\right) \rightarrow\{1,2,3\}$ sebagai berikut. Misalkan $x, y \in K_{m}, u_{i}, v_{i} \in K_{n i}, u_{j}, v_{j} \in$ $K_{n j} ; i=j=\{1,2, \cdots, n\}$, berikan pewarnaan $c(E(x y))=1, c\left(x u_{i}\right)=c\left(y u_{i}\right)=$ 2 dan $c\left(x v_{i}\right)=c\left(y v_{i}\right)=3 ; i=1,2, \cdots, n$. Misalkan $u_{i} \in K_{n i} \operatorname{dan} v_{j} \in$ $K_{n j}$ maka $u_{i} P v_{j}$ merupakan rainbow path yaitu $u_{i} x y v_{j}$ atau $u_{i} y x u_{j}$. Hal ini mengakibatkan bahwa $K_{m} \diamond K_{n}$ memuat rainbow 3-coloring atau $\operatorname{rc}\left(K_{m} \diamond K_{n}\right) \leq$ 3

Akan ditunjukkan bahwa $r c\left(K_{m} \diamond K_{n}\right) \geq 3$, untuk $m, n \geq 4$. Misalkan terdapat rainbow 2-coloring pada graf $\left(K_{m} \diamond K_{n}\right)$. Definisikan suatu pewarnaan $c^{\prime}\left(K_{m} \diamond K_{n}\right) \rightarrow\{1,2\}$ maka tidak mungkin terdapat rainbow path untuk dua titik sebarang $u v$ pada $K_{m} \diamond K_{n}$, karena $\operatorname{diam}\left(u_{i} v_{j}\right)=3$. Sehingga haruslah $r c\left(K_{m} \diamond K_{n}\right) \geq 3$. Dapat disimpulkan bahwa $3 \leq r c\left(K_{m} \diamond K_{n}\right) \leq 3$, sehingga haruslah $\operatorname{rc}\left(K_{m} \diamond K_{n}\right)=3$.

(Kasus 2.) Untuk $G \cong P_{m}$ dan $H \cong K_{n}$. Berdasarkan Proposisi 3.1(3), maka $r c\left(P_{m}\right)=m-1$. Pada graf $P_{m} \diamond K_{n}$ akan terdapat sebanyak $n-1$ graf lengkap $K_{2+n}$. Berdasarkan Proposisi 3.1(1), maka $r c\left(K_{2+n}=1\right.$. Misalkan terdapat rainbow (n-1) coloring pada graf $\left(P_{m} \diamond K_{n}\right)$. Definisikan suatu pewarnaan $c\left(K_{m} \diamond K_{n}\right) \rightarrow\{1,2, \cdots,(m-1)\}$. Misalkan $V\left(P_{m}\right)=\left\{v_{1}, v_{2}, \cdots, v_{m}\right\}, E\left(P_{m}\right)=\left\{v_{i} v_{i+1} ; i=\{1,2, \cdots, n-1\}\right.$ dan $V\left(K_{n}\right)=\left\{x_{1}, x_{2}, \cdots, x_{n}\right\}, E\left(K_{n}\right)=\left\{x_{i} x_{i+1} ; i=\{1,2, \cdots, n-1\}\right.$. Maka berikan pewarnaan $c\left(v_{i} v_{i+1}\right)=c\left(v_{i} x_{i}\right)=c\left(v_{i+1} x_{i+1}\right)=i ; i=1,2, \cdots, n-1$. Maka untuk setiap dua titik pada graf $P_{m} \diamond K_{n}$ akan terdapat rainbow path. Hal ini mengakibatkan bahwa $P_{m} \diamond K_{n}$ merupakan rainbow $(m-1)$ coloring atau $r c\left(P_{m} \diamond K_{n}\right) \leq m-1$.

Akan ditunjukkan bahwa $\operatorname{rc}\left(P_{m} \diamond K_{n}\right) \geq m-1$. Misalkan terdapat rainbow ( $m$-2) - coloring pada graf $P_{m} \diamond K_{n}$, maka tidak terdapat lintasan rainbow untuk dua titik ujung pada $P_{m}$. Haruslah $r c\left(P_{m} \diamond K_{n}\right)>m-2$. Dapat disimpulkan bahwa $m-2<\operatorname{rc}\left(P_{m} \diamond K_{n}\right) \leq m-1$ atau $r c\left(P_{m} \diamond K_{n}\right)=m-1$.

(Kasus 3.) Untuk $G \cong C_{m}$ dan $H \cong K_{n}$.

Berdasarkan Proposisi 3.2, $r c\left(C_{m}\right)=\left\lceil\frac{n}{2}\right\rceil$. Pada graf $C_{m} \diamond K_{n}$ akan terdapat sebanyak $n$ buah graf lengkap. Akan kita kelompokkan pewarnaan pada graf $C_{m} \diamond K_{n}$ berdasarkan banyaknya titik pada graf siklus $C_{m}$.

Jika titik pada graf siklus adalah genap, misalkan $m=2 k$ untuk bilangan bulat $k \geq 2$ maka $r c\left(C_{m}\right) \geq \operatorname{diam}\left(C_{m}\right)=k$. Pewarnaan sisi $c_{0}$ dari $C_{m}$ didefinisikan oleh $c_{0}\left(e_{i}\right)=i$ untuk $1 \leq i \leq k$, dan $c_{0}\left(e_{i}\right)=i-k$ untuk $k+1 \leq i \leq n$. Misalkan $V\left(C_{m}\right)=\left\{x_{1}, x_{2}, \cdots, x_{m}\right\}, E\left(C_{m}\right)=\left\{x_{i} x_{i+1} \mid 1 \leq i \leq n\right\}$ dan him- 
punan titik pada $K_{n}$ adalah $V\left(K_{n}\right)=\left\{y_{1}, y_{2}, \cdots, y_{n}\right\}, E\left(K_{n}\right)=\left\{\left\{y_{i} y_{j}\right\} ; i, j \in\right.$ $\{1,2, \cdots, n, i \neq j\}$. Definisikan pewarnaan pada sisi-sisi $n$ buah graf lengkap siklus $C_{m}$, yaitu

$$
c_{0}\left(x_{i} x_{i+1}\right)=c_{0}\left(x_{i} C_{n}\right)=c_{0}\left(x_{i+1} C_{n}\right) ; i=1,3, \cdots, n-1 .
$$

Kemudian untuk $k$ buah graf lengkap yang belum memperoleh pewarnaan, berikan pewarnaan baru untuk sisi graf lengkap yang bukan siklusnya $\left(x_{i} C_{n}\right)$ dan $x_{i+1} C_{n}$ yaitu $c_{0}\left(\left\lceil\frac{n}{2}\right\rceil+1\right)$ dan untuk siklusnya $c_{0}\left(e_{i}\right)=i-k$. Maka untuk setiap dua titik pada graf $C_{m} \diamond K_{n}$ akan terdapat rainbow path, sehingga $r c\left(C_{m} \diamond\right.$ $\left.K_{n}\right) \leq k+1 ; n=2 k$.

Kemudian akan ditunjukkan $r c\left(C_{m} \diamond K_{n}\right) \geq k+1$. Misalkan $r c\left(C_{m} \diamond K_{n}\right)=k$ dengan pewarnaan $c_{0}\left(C_{m} \diamond K_{n}\right) \rightarrow\{1,2, \cdots, k\}$, maka untuk setiap dua titik pada $K_{n i}$ dan $K_{n j}$ tidak akan terdapat rainbow path, karena diam $\left(C_{m} \diamond K_{n}\right)=$ $k+1$. Jadi haruslah $r c\left(C_{m} \diamond K_{n}\right)>k$ atau $r c\left(C_{m} \diamond K_{n}\right) \geq k+1$. Karena $r c\left(C_{m} \diamond K_{n}\right) \leq k+1$ dan $r c\left(C_{m} \diamond K_{n}\right) \geq k+1$, maka $k+1 \leq r c\left(C_{m} \diamond K_{n}\right) \leq k+1$. Dapat disimpulkan bahwa untuk $n$ genap, berlaku $\operatorname{rc}\left(C_{m} \diamond K_{n}\right)=k+1$.

Misalkan banyaknya titik pada graf lingkaran adalah ganjil. Misalkan $m=$ $2 k+1$ untuk bilangan bulat $k \geq 2$ maka $\operatorname{rc}\left(C_{m}\right) \geq \operatorname{diam}\left(C_{m}\right)=k$. Pewarnaan sisi $c_{1}$ dari $C_{m}$ didefinisikan oleh $c_{1}\left(e_{i}\right)=i$ untuk $1 \leq i \leq k+1$ dan $c_{1}\left(e_{i}\right)=i-k-1$ jika $k+2 \leq i \leq m$. Kemudian definisikan pewarnaan pada sisi-sisi $n$ buah graf lengkap pada siklus $C_{m}$ yaitu $c_{1}\left(x_{i} x_{i+1}\right)=c_{0}\left(x_{i} y_{i}\right)=$ $c_{0}\left(x_{i+1} y_{i+1}\right) ; i=\{1,3, \cdots, m-1\}$. Kemudian untuk $k-1$ buah graf lengkap yang belum memperoleh pewarnaan, berikan pewarnaan $c_{1}: E\left(C_{m} \diamond K_{n}\right) \rightarrow$ $\{1,2, \cdots, k+1\}$. Maka untuk setiap dua titik pada graf $C_{m} \diamond K_{n}$ akan terdapat rainbow path, sehingga $\operatorname{rc}\left(C_{m} \diamond K_{n}\right) \leq k+1 ; n=2 k+1$.

Kemudian akan ditunjukkan $r c\left(C_{m} \diamond K_{n}\right) \geq k+1$. Misalkan $r c\left(C_{m} \diamond K_{n}\right)=k$ maka berdasarkan Proposisi 2.4, haruslah $r c\left(C_{m}\right)=k+1$, karena jika $r c\left(C_{m}\right)=$ $k$ akan mengakibatkan tidak ada lintasan rainbow untuk $x_{i}, x_{j}$ sebarang pada $C_{m}$. Hal ini mengakibatkan $r c\left(C_{m} \diamond K_{n}\right)>k$, karena $C_{m} \subset\left(C_{m} \diamond K_{n}\right)$. Maka haruslah $\operatorname{rc}\left(C_{m} \diamond K_{n}\right)>k$ atau $r c\left(C_{m} \diamond K_{n}\right) \geq k+1$. Diperoleh $k+1 \leq$ $\operatorname{rc}\left(C_{m} \diamond K_{n}\right) \leq k+1$ atau $r c\left(C_{m} \diamond K_{n}\right)=k+1$.

Berdasarkan ketiga kasus diatas, diperoleh bahwa $r c\left(C_{m} \diamond K_{n}\right) \geq k+1$, dengan $k=\operatorname{diam}\left(C_{m}\right)=\left\lfloor\frac{m}{2}\right\rfloor$, sehingga $r c\left(C_{m} \diamond K_{n}\right)=\left\lfloor\frac{m}{2}\right\rfloor+1$.

Selanjutnya akan dikaji bilangan rainbow connection pada corona sisi antara graf yang sama, yaitu graf lengkap dengan graf lengkap dan graf lintasan dengan graf lintasan.

Akibat 4.3. Misal terdapat graf lengkap $K_{m}$ dan $K_{n}$, maka $\operatorname{rc}\left(K_{m} \diamond K_{n}\right)=\operatorname{rc}\left(K_{n} \diamond\right.$ $\left.K_{m}\right)=3 ; m, n \geq 4$.

Bukti. Dapat ditunjukkan bahwa $K_{m} \diamond K_{n} ¥ K_{n} \diamond K_{m}$. Selanjutnya, dengan metode pembuktian yang sama dengan Teorema $4.2(1)$, diperoleh bahwa $\operatorname{rc}\left(K_{m} \diamond K_{n}\right)=$ $3 ; m \geq 4, n \geq 1$. Berdasarkan hal tersebut dapat diperoleh $\operatorname{rc}\left(K_{n} \diamond K_{m}\right)=3 ; m, n \geq$ 4. Disimpulkan bahwa $r c\left(K_{m} \diamond K_{n}\right)=\operatorname{rc}\left(K_{n} \diamond K_{m}\right)=3 ; m, n \geq 4$. 
Pada teorema berikut diberikan bilangan rainbow connection untuk corona sisi antara graf lintasan dengan graf lintasan.

Teorema 4.4. Misal terdapat dua graf lintasan $P_{m}$ dan $P_{n} ; m, n \geq 3$, maka

$$
r c\left(P_{m} \diamond P_{n}\right)= \begin{cases}m-1, & \text { untuk } m \geq n, \\ m+1, & \text { untuk } m<n .\end{cases}
$$

Bukti. Perhatikan dua kasus berikut.

(Kasus 1.) Untuk $G \cong P_{m}$ dan $H \cong P_{n}$ dengan $m \geq n$.

Misalkan himpunan titik pada $P_{m}$ adalah $V\left(P_{m}\right)=\left\{x_{1}, x_{2}, \cdots x_{m}\right\}$ dan himpunan titik pada $P_{n}$ adalah $V\left(P_{n}\right)=\left\{v_{1}, v_{2}, \cdots v_{n}\right\}$. Definisikan suatu pewarnaan pada sisi-sisi $P_{m} \diamond P_{n}$ yaitu (m-1)-coloring $c: E\left(P_{m} \diamond P_{n}\right) \rightarrow$ $\{1,2, \cdots, m-1\}$ sebagai berikut. Untuk $m=n$, berikan pewarnaan rainbow connection pada graf $P_{m}$ yang sama dengan setiap duplikat pada graf $P_{n}$; $c\left(P_{m}\right)=c\left(P_{n}\right)$. Selanjutnya, $c\left(x_{i} x_{i+1}\right)=c\left(x_{i} v_{i}\right)=c\left(x_{i+1} v_{i}\right)$. Sedangkan untuk $m>n$, berikan pewarnaan rainbow connection yang sama dengan kasus $m=n$, akan tetapi karena $m>n$ maka berikan pewarnaan $c: E\left(P_{n}\right)=1,2, \cdots, n$. Maka untuk setiap dua titik pada $P_{m} \diamond P_{n}$ akan terdapat rainbow path. Sehingga $r c\left(P_{m} \diamond P_{n} ; m \geq n\right)=m-1$.

(Kasus 2.) Untuk $G \cong P_{m}$ dan $H \cong P_{n}$ dengan $m<n$.

Berikan pewarnaan pada $P_{m} \diamond P_{n}$ sesuai dengan kasus $m \geq n$. Bedanya pada $c\left(x_{i} P_{n}\right)=m$ dan $c\left(y_{i} P_{n}\right)=m+1$. Maka untuk setiap dua titik $P_{m} \diamond P_{n}$ akan terdapat rainbow path. Sehingga $r c\left(P_{m} \diamond P_{n} ; m<n\right)=m+1$.

\section{Ucapan Terima Kasih}

Penulis mengucapkan terima kasih kepada Bapak Dr. Admi Nazra, Bapak Dr. Mahdhivan Syafwan dan Ibu Dr. Yanita yang telah memberikan masukan dan saran, sehingga tulisan ini dapat diselesaikan dengan baik.

\section{Daftar Pustaka}

[1] Bondy, J.A., U.S.R. Murty, 2008. Graph Theory, Graduated Texts In Mathematics. Springer. New York.

[2] Chartrand, G., G.L. Johns, K.A. McKeon, P. Zhang, 2008. Rainbow connection in graphs, Math. Bohem.: $85-98$

[3] Diestel, Reinhard, 2005. Graph Theory, Electronic Edition 3. New York.

[4] Hou, Y. dan W. C. Shiu, 2010. The Spectrum of The Edge Corona of Two Graph. Electronic Journal of Linear Algebra 20: 586 - 594

[5] Ramya, N. K. Rangarajan, R. Sattanathan, 2012. On Rainbow Coloring of Some Classes of Graphs, International Journal of Computer Applications, 46(18): 0975 - 8887

[6] Estetikasari, D., Sy. Syafrizal. 2013. Rainbow Connection Number for Some Corona Graph, Applied Mathematical Sciences 7(100): 4975 - 4980

[7] Frucht, R. and F. Harary, 1970. On the corona two graphs. Aequationes Math (4): $322-325$ 